\title{
Neoformación eritematosa en tronco
}

\section{Erythematous neoformation in trunk}

\author{
Myrna Rodríguez-Acar, ${ }^{\star}$ Alberto Ramos-Garibay, ${ }^{\ddagger}$ Raphael Mejía-Granilla ${ }^{\S}$
}

\section{CASO CLÍNICO}

Hombre de 37 años de edad, originario y residente del Estado de México, soldador; acude por presentar una dermatosis localizada a tronco, del cual compromete la región infraclavicular izquierda (Figuras 1 y 2). Dicha dermatosis está constituida por una neoformación eritematosa oval de $3.5 \times 2.5 \mathrm{~cm}$, y 1 $\mathrm{cm}$ de altura, bien delimitada, infiltrada, ulcerada en el centro y unilateral.

Al interrogatorio refiere haber iniciado 30 días antes de su primera consulta en esta unidad con un «granito» que fue incrementando su tamaño rápidamente, formándose una ulceración en el centro. De evolución aguda y asintomática.

Sin antecedentes personales patológicos. Sin tratamiento previo.

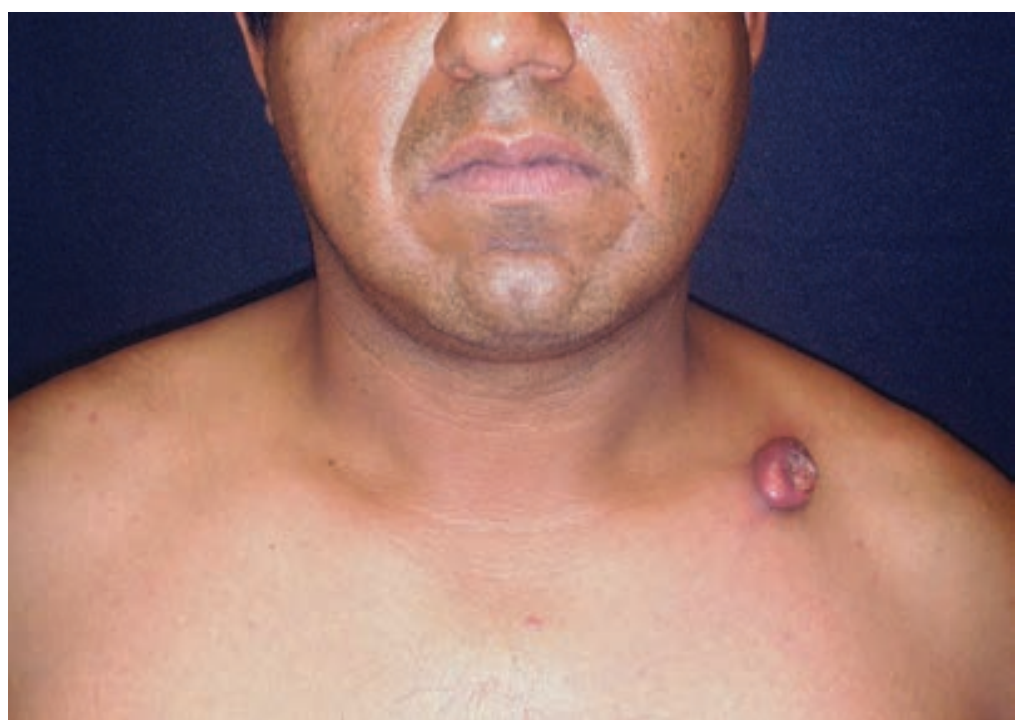

Figura 1: Neoformación en cara anterior de tórax.

* Dermatóloga.

‡ Dermatopatólogo.

$\S$ Dermatólogo, práctica privada.
Citar como: Rodríguez-Acar M, Ramos-Garibay A, Mejía-Granilla R. Neoformación eritematosa en tronco. Rev Cent Dermatol Pascua. 2020;29 (1):26-31. https://dx. doi. org/10.35366/96267 


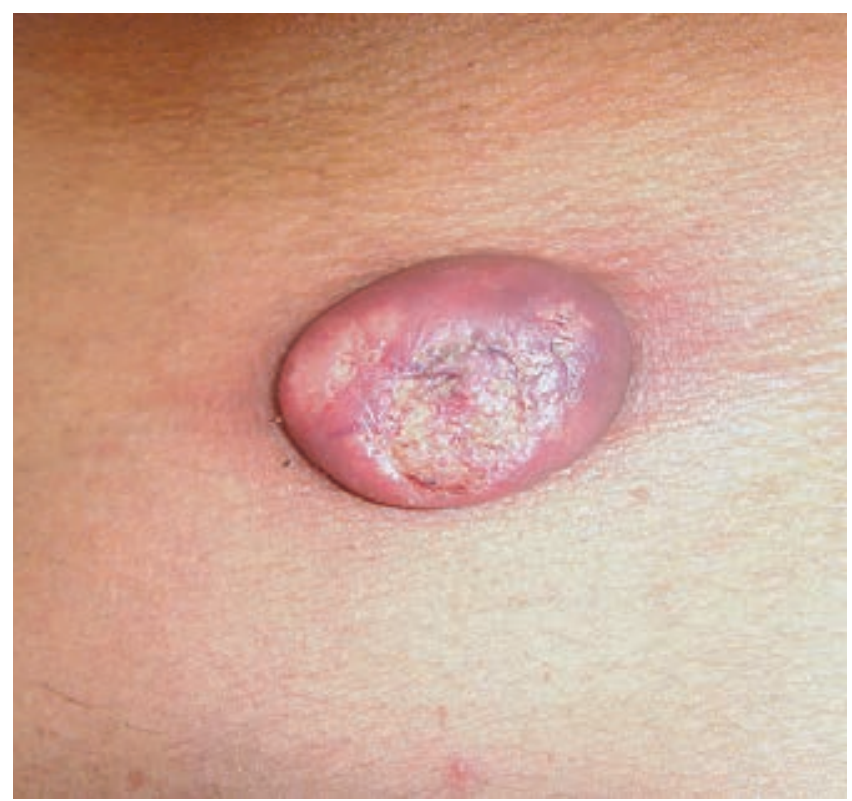

Figura 2: Acercamiento de la lesión.

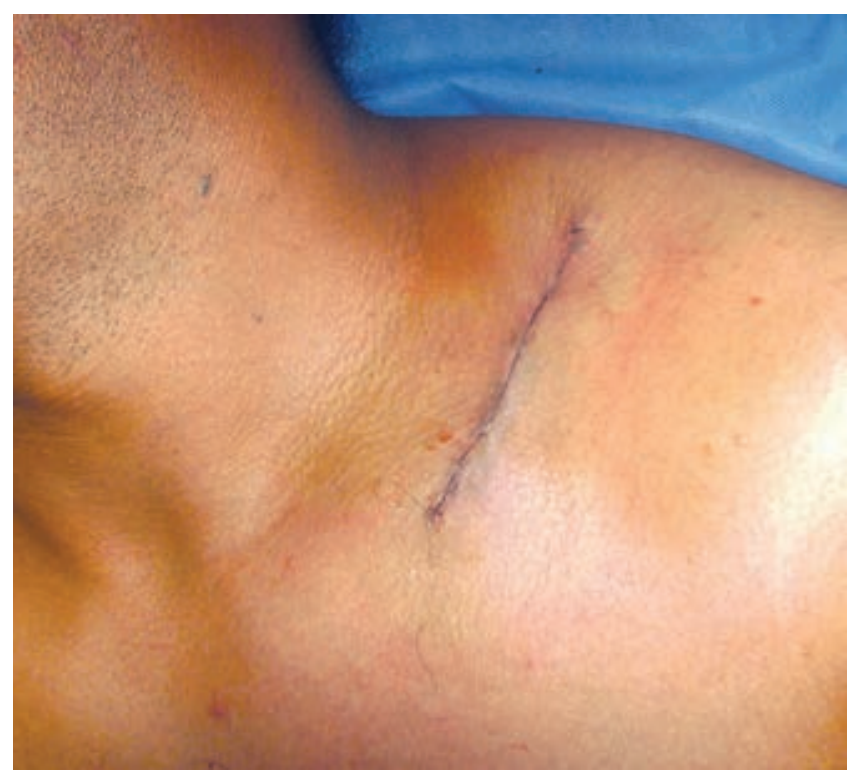

Figura 3: Inmediatamente después del procedimiento quirúrgico.

Se realizó biopsia excisional con márgenes de $6 \mathrm{~mm}$ (Figura 3), los cambios histopatológicos se observan en las Figuras 4 y 5.

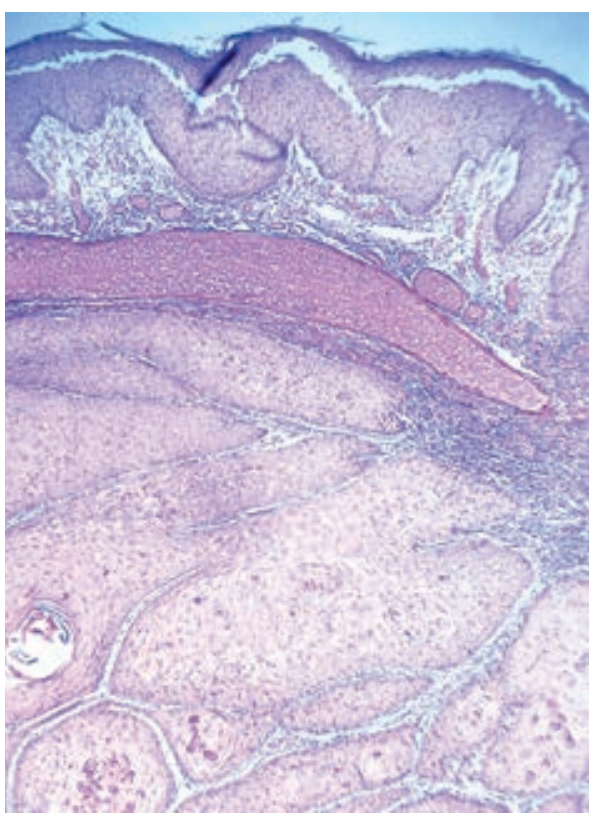

Figura 4:

Estudio histopatológico. Lesión exofítica con hiperqueratosis paraqueratósica y algunos sitios con depósitos de fibrina. Tinción con hematoxilina y eosina (H\&E 4X).

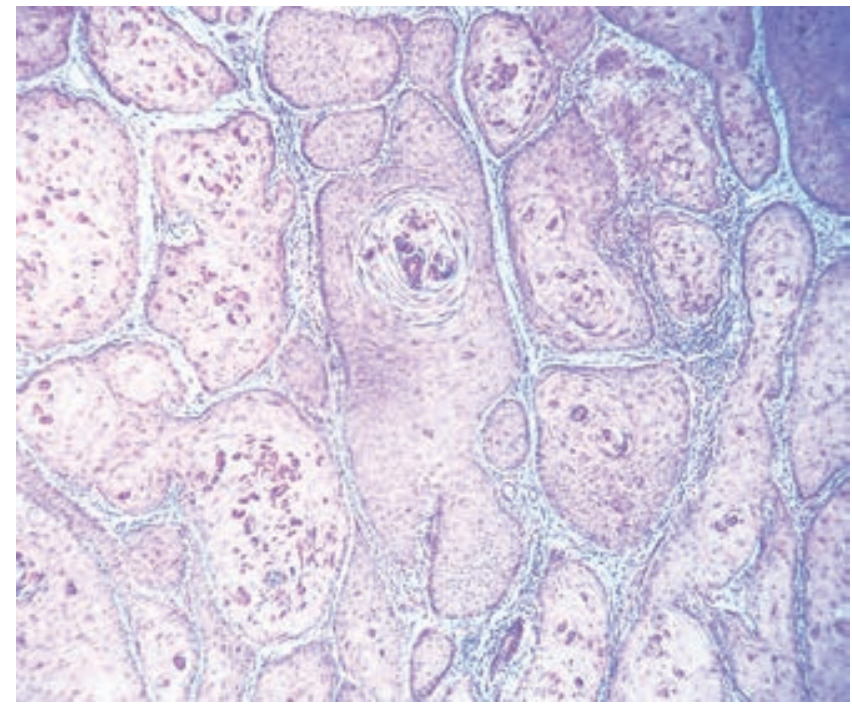

Figura 5: A mayor aumento: en todo el espesor de la dermis hay cordones tumorales que se desprenden de la epidermis y recuerdan a las células espinosas. En el interior de dichos cordones hay abundantes células disqueratósicas y globos córneos. Tinción con hematoxilina y eosina (H\&E 10x).
Con los datos clínicos e histopatológicos proporcionados, ¿cuál es su diagnóstico? 


\section{CARCINOMA EPIDERMOIDE BIEN DIFERENCIADO}

\section{INTRODUCCIÓN}

El carcinoma epidermoide (CE) es la segunda neoplasia cutánea maligna más frecuente originada en los queratinocitos, después del carcinoma basocelular (CBC). A diferencia de éste, se le asocia con riesgo importante de producir metástasis.

Se origina de la epidermis, o bien del epitelio de las mucosas oral y genital. ${ }^{1,2}$

\section{EPIDEMIOLOGÍA Y FACTORES DE RIESGO}

La incidencia anual es variable debido a factores raciales y geográficos como la altitud; sin embargo, a nivel global, constituye $20 \%$ de los tipos de cáncer queratinocíticos. ${ }^{1}$ La incidencia ajustada por edad entre la población blanca es de 100 a 150 por 100,000 habitantes por año, y la incidencia específica por edad entre las personas mayores de 75 años es aproximadamente 10 veces esa tasa. La incidencia se duplica con cada decremento de ocho a 10 grados de latitud geográfica. En lugares cercanos al ecuador, y en altitudes mayores, las cifras de CE son más altas. ${ }^{2}$

Se manifiesta principalmente en personas del sexo masculino en una proporción de 2 a 4.1; sin embargo, en la población mexicana en estudios realizados por Peniche y colaboradores esta cifra fue de 1.3 a $1 .^{2} \mathrm{La}$ edad de presentación más frecuente es entre 50 y 66 años. ${ }^{3} \mathrm{El}$ incremento de la enfermedad se debe a una mayor exposición a radiación ultravioleta e ionizante, disminución de la capa de ozono, cambios en el estilo de vestir, que permite una mayor exposición al sol, incremento en la longevidad, fenotipo cutáneo claro, ser portador de alguna genodermatosis (xeroderma pigmentoso, albinismo, epidermodisplasia verruciforme, etcétera), inmunosupresión, infección por virus del papiloma humano tipos $6,11,16,18$, exposición a carcinógenos químicos (arsénico, hidrocarburos aromáticos) úlceras crónicas, cicatrices, procesos inflamatorios crónicos, y terapias con PUVA. ${ }^{2}$

\section{Etiopatogenia}

En el CE se ha identificado una alta frecuencia de mutaciones en el gen supresor tumoral p53 inducidas por la radiación ultravioleta (58-69\%). Este gen que se ubica en el brazo corto del cromosoma 17, codifica una fosfoproteína nuclear de $53 \mathrm{Kd}$, la cual le otorga el nombre. Ésta actúa como factor regulador transcripcional, especialmente en respuesta a daño en el ADN. Este gen tiene un papel importante en el mantenimiento de la integridad del genoma, debido a que la pérdida de su función permite la sobrevida de elementos celulares genéticamente dañados que con el tiempo conducen a transformación celular maligna. Como consecuencia del efecto crónico de la radiación ultravioleta, los queratinocitos con el gen p53 mutado y disfuncional no entran en apoptosis, lo que conlleva a una expansión clonal y a una proliferación incontrolada de células anormales. Por otro lado, también se han detectado mutaciones activadoras en el gen RAS en 35 a $45 \%$ de los CE. Estas alteraciones influyen negativamente en diversos procesos celulares, por ejemplo, la proliferación celular. En el CE se han observado deleciones o pérdidas en las siguientes regiones cromosómicas: $9 p, 3 p, 18 q, 17 p, 4 q, 5 q, 8 p, 11 p, 13 q, 18 q$ así como ganancias en los cromosomas 3q, 14q, Xq, 4p, 8q, 1q, $5 p, 7 q, 9 q, 10 q$ y $20 q .^{2}$

Todas las alteraciones anteriormente descritas se han detectado tanto en el CE como en su precursor, la queratosis actínica, lo cual evidencia una relación clonal entre ambos. ${ }^{2}$

\section{Manifestaciones clínicas}

La más frecuente es la afectación de la cabeza y el cuello en $55 \%$, seguida de manos y antebrazos (18\%). ${ }^{1}$ El tronco se ve comprometido sólo en $4 \%$. El sitio anatómico en el cual se ubica la lesión cambia el pronóstico en cuanto a recurrencia y potencial metastásico, por ejemplo, la zona de labios y orejas tiene una recurrencia entre 2 y $20 \%$, con metástasis entre 5 y $19 \%$ de los casos. El tamaño de la neoformación al momento del diagnóstico es muy importante, se considera de alto riesgo si es $>2 \mathrm{~cm}$. En estos casos se asocia con tasas de recurrencia de 7\%, y metástasis en $9-30 \%$ de los casos. Las Guías de Práctica Clínica de Estados Unidos sugieren considerar CE de alto riesgo aquél que se ubica en áreas anatómicas como piel cabelluda, frente, mejillas y cuello ${ }^{3-5}$ así como los que tengan un diámetro $>1 \mathrm{~cm}$ localizados en la zona «H» de la cara, y los que comprometan genitales, palmas-plantas con un tamaño $>0.6 \mathrm{~cm}^{2,5}$

Generalmente se manifiesta como una neoformación de forma redonda u oval, eritematosa, infiltrada, de bordes bien definidos, superficie anfractuosa, cubierta por una fina escama blanquecina, en ocasiones con un cráter de queratina en el centro, costras sanguíneas, o 
una exulceración. Su evolución es subaguda o crónica asintomática.

El desarrollo de un CE en sitios de inflamación crónica cómo úlceras, sitios postradiación, etcétera, muestran un comportamiento biológico más agresivo. En estos casos el riesgo de diseminación es de $26-38 \%$. $^{2}$

Al momento del interrogatorio y exploración física se deben buscar intencionadamente los síntomas neurológicos asociados a invasión neural y perineural, por ejemplo: dolor neuropático, parestesias, alteraciones de los pares craneales V, VII. La presencia de estos síntomas al momento del diagnóstico sugiere mayor riesgo de no lograr control local de la enfermedad (80 contra $54 \%$ en pacientes sin síntomas neurológicos)..$^{2-4}$

\section{Inmunosupresión y carcinoma epidermoide}

En cuanto a la búsqueda intencionada de esta neoplasia en pacientes con factores de riesgo, la población principal es aquélla que ha sido sometida a un trasplante, ${ }^{6}$ portadora de un fototipo cutáneo claro. Este grupo tiene un riesgo de más de 100 veces de desarrollar algún tumor maligno, y de este porcentaje, $65-84 \%$ corresponde a un CE. 2,5 En estos casos el tumor aparece a una edad más temprana, aproximadamente de tres a cinco años posterior al trasplante, en piel expuesta al sol, con mayor número de tumores por paciente (16.5 tumores). Su comportamiento clínico e histológico es más agresivo, con un riesgo incrementado de metástasis, y con un incremento en la mortalidad entre $27 \mathrm{y}$ $63 \%$. El examen clínico y el interrogatorio en ellos debe estar enfocado en detectar factores de riesgo tales como historia familiar de neoplasias, exposición solar aguda en la infancia, o crónica intermitente, queratosis actínicas, poroqueratosis, infección previa por virus del papiloma humano, tipo de quimioterapia utilizada en el tratamiento del trasplante de base, tiempo de duración del mismo, e inmunosupresores administrados, cantidad de linfocitos CD4, y si cursan o no con linfopenia. ${ }^{1,2,5}$

El diagnóstico oportuno y el tratamiento temprano y agresivo marcan la diferencia en el pronóstico. ${ }^{5}$

El incremento en la incidencia de CE en pacientes trasplantados está bien documentado. Aquéllos que han sido sometidos a cirugía de corazón tienen un riesgo relativo de desarrollarlo hasta en $108 \%$ más, comparado con la población general. ${ }^{2}$

El periodo de latencia desde el momento del trasplante hasta el desarrollo del carcinoma varía de uno a siete años, dependiendo del tipo y grado de inmunosupresión. ${ }^{2}$

Los factores que contribuyen al desarrollo de CE en estos pacientes incluyen la edad del paciente al momento del trasplante, pertenecer al sexo masculino, fototipo cutáneo claro, la duración y el tipo del tratamiento inmunosupresor, historia de exposición intensa a radiación UV, antecedente de infección por virus del papiloma humano, comorbilidades previas, e historia de CE previo. La inmunosupresión puede deprimir la función de vigilancia inmunológica que actúa para destruir células mutantes, potencialmente malignas. ${ }^{2}$

Los fármacos inmunosupresores también pueden potenciar el efecto carcinogénico de la radiación ultravioleta. En algunos pacientes que utilizan estos medicamentos para el tratamiento de artritis reumatoide, enfermedad inflamatoria del intestino, y procesos linfoproliferativos, la incidencia de CE es cinco veces mayor que la esperada en la población general. ${ }^{2}$

Pacientes infectados por virus de la inmunodeficiencia humana desarrollan CE a edades más tempranas que la población general, lo cual incrementa su morbilidad y mortalidad. ${ }^{2}$

\section{DIAGNÓSTICO}

La sospecha clínica es la base de este apartado. Se deben tomar en cuenta las características de topografía y morfología, así como los factores antes señalados.

La realización de un estudio histopatológico es importante, ${ }^{7}$ ya que el subtipo histológico se ha considerado un factor determinante en el pronóstico de estos pacientes. ${ }^{8}$

Con este estudio se observa que dicho tumor se caracteriza por estar constituido por una proliferación de queratinocitos atípicos, que se extienden desde la epidermis hacia la dermis. Se aprecia pleomorfismo celular y nuclear, nucleolos prominentes, células multinucleadas y figuras mitóticas atípicas. Puede haber queratinización celular individual y pequeños focos de queratinización incompleta, llamados perlas córneas. ${ }^{2,8}$

Además de los hallazgos anteriores, específicamente en este tipo de tumor, el patólogo debe indicar claramente el grado de diferenciación. Se clasifica como bien diferenciado, moderadamente diferenciado y poco o indiferenciado, dependiendo de la proporción observada entre las células bien diferenciadas hacia una estructura epidérmica normal en relación con las indiferenciadas, que no se asemejan a ninguna de dichas estructuras. Lo anterior es muy importante para decidir el manejo a seguir. ${ }^{1,2}$ Los CE con mala diferenciación pueden producir metástasis entre 33 y $58 \%$. 2,9

Se han descrito varios subtipos histológicos: queratoacantoma, acantolítico, de células fusiformes, verrugoso, de células claras, papilar, en anillo de sello, pigmentado y desmoplásico. ${ }^{1,2}$ 
Se consideran factores de alto riesgo histológico cuando el tumor tiene una profundidad $>2 \mathrm{~mm}$, los tipos desmoplásico, acantolítico, y de células fusiformes así como la detección de invasión perineural. ${ }^{6}$

En pacientes con un CE de alto riesgo es importante realizar la exploración ganglionar. Se recomienda que ésta sea bilateral. ${ }^{2,10}$

Está indicado también solicitar estudios de imagen cuando existen ganglios palpables, por ejemplo: tomografía computarizada, ultrasonido y resonancia magnética. ${ }^{2}$

\section{Auxiliares diagnósticos}

Una de las herramientas que apoyan el diagnóstico clínico es el empleo de la dermatoscopía. ${ }^{7}$ Aunque su sensibilidad y especificidad son mayores en el estudio de tumores melanocíticos o en el CBC, en esta patología se sugiere su empleo para descartar otras patologías. En una serie de casos con diagnóstico inicial de CE empleando un dermatoscopio, se reportó en $38 \%$ de los pacientes, después de realizar el estudio histopatológico, que se trataba de melanoma maligno nodular hipomelanótico o amelánico, lo cual corrobora la importancia de verificar la sospecha detectada con esta herramienta médica con el estudio antes descrito. ${ }^{2}$

En el carcinoma epidermoide los elementos principalmente descritos con esta técnica son:

- Área de queratina central (32\%).

- Estructuras blanquecinas (66\%).

- Círculos blanquecinos (32\%).

- Perlas de queratina en mosaico (14\%).

- Hemorragia (72\%).

- Collarete (12\%).

- Patrón vascular polimorfo (50\%).

- Vasos glomerulares (42\%).

- Vasos lineales irregulares (36\%).

- Vasos en horquilla (30\%). ${ }^{6}$

\section{Microscopía confocal}

Los avances en la visualización cutánea in vivo, de alta resolución, no invasiva pueden ayudar a superar en ocasiones algunas limitaciones observadas con el estudio histopatológico. La microscopía confocal por reflexión ofrece una visualización de alta resolución. Las características histopatológicas al emplear esta técnica incluyen observar a mayor aumento el tamaño del núcleo de las células epidérmicas, estos núcleos se aprecian agrandados, con pleomorfismo y paraqueratosis en un patrón de desorganización arquitectónica. Cuando estas características displásicas se observan en todo el espesor de la epidermis, indican que se trata de un CE. También se observan algunos patrones vasculares. ${ }^{2}$

Para estadificar cada caso se deben tomar en cuenta las características histológicas, si hay o no invasión tumoral, invasión perineural, el grado de diferenciación y la profundidad de la invasión. ${ }^{2}$

El retraso en el diagnóstico disminuye cuando el paciente acude directamente con un dermatólogo (OR $=0.45 ;$ IC $95 \%)^{7}$

\section{TRATAMIENTO}

Se considera la extirpación quirúrgica como el tratamiento de elección. Las opciones incluyen realizar cirugía micrográfica de Mohs, ${ }^{4}$ la cirugía con verificación de lecho y/o márgenes en el transoperatorio, y la cirugía convencional con márgenes amplios. ${ }^{11}$ Se prefieren las técnicas que verifican la remoción completa de la neoplasia antes del cierre o reconstrucción. ${ }^{2}$ Se debe realizar una adecuada extirpación quirúrgica, con márgenes entre 4 y $10 \mathrm{~mm}$, dependiendo del tamaño del tumor. En lesiones tumorales menores de $2 \mathrm{~cm}$ de diámetro, bien diferenciadas, sin invasión del tejido celular subcutáneo, ubicadas en tronco o extremidades con márgenes de 4 mm se tiene una curación de $95 \% .{ }^{2}$ Los tumores de mayor tamaño, menos diferenciados, que invaden la grasa subcutánea, localizados en áreas de alto riesgo como la región centrofacial, pabellones auriculares, zonas preauriculares o retroauriculares, sienes, piel cabelluda, genitales, manos o pies, requieren al menos $6 \mathrm{~mm}$ o más de margen para alcanzar bordes libres. En estos casos es preferible realizar cirugía micrográfica de Mohs, ${ }^{2,4,11}$ la cual es el tratamiento de elección en los CE de alto riesgo. Con ésta se consigue la mayor tasa de curación a los cinco años, y la mayor conservación de tejido sano.

Aunque las tasas de curación son más altas con este procedimiento que con la cirugía convencional, éstas disminuyen en el caso de tumores mayores de $2 \mathrm{~cm}$ de diámetro, apenas diferenciados o recurrentes. Otra indicación para realizar esta cirugía sería el caso de los CE con infiltración perineural, con invasión ósea, o por afectación por contigüidad a una glándula. , $^{2,9}$

Otras alternativas como la crioterapia, la electrodesecación, el curetaje, láser, el empleo de fármacos por vía tópica, como el imiquimod, el 5-fluorouracilo, los retinoides tópicos o la terapia fotodinámica, no se recomiendan para eliminar un CE que tenga factores de alto riesgo. ${ }^{2,11}$ 
El paciente con enfermedad localmente avanzada o metastásica se beneficiará del tratamiento multidisciplinario: cirugía oncológica, oncología médica, radiooncología, etcétera. ${ }^{2,7,10,11}$

Por otro lado, está indicada la extirpación selectiva del ganglio centinela en los CE de cabeza y cuello, lo cual cuenta con una sensibilidad de $90 \%{ }^{2}$

\section{PRONÓSTICO}

EI CE tiene una tendencia significativa a desarrollar metástasis. La incidencia reportada fluctúa entre 0.5 y $16 \%$. Las metástasis y la invasión tumoral varían en relación a diversos factores denominados de riesgo, por ejemplo, aquellos CE que se desarrollan sobre cicatrices de quemaduras, radiación previa, queratosis arsenicales, ubicación en mucosas o uniones mucocutáneas (labio y pabellón auricular), mayores de $2 \mathrm{~cm}$, lesiones que invaden dermis reticular y tejido celular subcutáneo, lesiones mayores de $4 \mathrm{~mm}$ de grosor, de rápido crecimiento, indiferenciadas o con invasión perineural, neoplasias en pacientes con inmunosupresión, y las recurrentes. ${ }^{2,3,5}$

La recurrencia entre 70 y $80 \%$ de los casos de CE se desarrolla en los primeros dos años, y $95 \%$ a los cinco años. En caso de enfermedad local, las revisiones serán cada tres a seis meses por dos años, luego cada seis a 12 meses por tres años y finalmente cada año, por tiempo indefinido. Pacientes con enfermedad locorregional deben citarse cada uno a tres meses durante un año, luego cada dos a cuatro meses en un año, posteriormente cada cuatro a seis meses durante tres años, y por último cada seis a 12 meses, lo que le reste de vida al paciente. Además del examen clínico, se debe preguntar siempre sobre la presencia de dolor local y parestesias así como explorar los pares craneales. ${ }^{2,8,10}$

\section{COMENTARIO}

Este caso se comunica con la finalidad de que el lector identifique de manera temprana una imagen y ubicación poco frecuentes de un carcinoma epidermoide para que se inicie a la mayor brevedad el plan de abordaje y el tratamiento oportuno para el mismo.

En el caso del paciente, motivo de esta publicación, se solicitaron estudios de extensión para descartar metástasis, los cuales resultaron negativos. Debido a que en el reporte histológico del estudio realizado en esta unidad nos comunicaron que la extirpación había sido incompleta en el lecho, se procedió a realizar otra intervención quirúrgica en el Servicio de Oncología del Hospital General de México, donde dieron un margen de $1 \mathrm{~cm}$, en esta ocasión reportando ya una extirpación completa. Después de un año no han presentado datos de actividad tumoral.

Por otro lado, es importante señalar que por la topografía y morfología poco frecuentes así como el rápido crecimiento de la neoplasia en este caso, se debe realizar diagnóstico diferencial clínico con un queratoacantoma, ya que la imagen clínica es muy parecida. Este diagnóstico se descartó en cuanto se obtuvo el resultado del estudio histopatológico. El manejo y el pronóstico son diferentes con este último tumor.

\section{BIBLIOGRAFÍA}

1. Telich TJE, Monter PA, Baldín AV, Apellaniz CA. Diagnóstico y tratamiento de los tumores malignos de piel. Acta Med. 2017; 15: 154-160.

2. Torres LV, Camacho MC, Sober-Ignacio SA. Dermatología práctica ibero-latinoamericana. 2ª ed., Tomo II, pp. 133.1-133.9.

3. Veness MJ, Porceddu S, Palme CE, Morgan GJ. Cutaneous head and neck squamous cell carcinoma metastatic to parotid and cervical lymph nodes. Head Neck. 2007; 29: 621-631.

4. Leibovitch I, Huilgol SC, Selva D, Hill D, Richards S, Paver R. Cutaneous squamous cell carcinoma treated with Mohs micrographic surgery in Australia I. Experience over 10 years. J Am Acad Dermatol. 2005; 53: 253-260.

5. DeSimone Ja, Pritesh SK, Schmults CD. Recognition and management of high-risk (aggressive) cutaneous squamous cell carcinoma. Up To Date. 2014. www.uptodate.com.

6. Stasko T, Brown MD, Carucci JA, Euvrard S, Johnson TM, Sengelmann $\mathrm{RD}$ et al. Guidelines for the management of squamous cell carcinoma in organ transplant recipients. Dermatol Surg. 2004; 30: 642-650.

7. Lin JM, Yan Pan, Jalilian C, W. Kelly JW. Dermoscopic characteristics of nodular squamous cell carcinoma and keratoacanthoma. Dermatol Pract Concept. 2014; 4: 9-15.

8. Renzi C, Mastroeni S, Mannooranparamil T, Passarelli F, Pasquini P. Timely diagnosis of cutaneous squamous cell carcinoma: the GP's role. Family Practice. 2011; 28: 277-279.

9. Brougham DN, Tan ST. Incidence and risk factors of metastasis for cutaneous squamous cell carcinoma-implications on the T-classification system. J Surg Oncol. 2014; 110: 876-882.

10. Nuño-González A, Vicente-Martina F, Pinedo-Moraleda F, LópezEstebaranz J. Carcinoma epidermoide cutáneo de alto riesgo. Actas Dermo-Sifiliog. 2012; 103: 567-578.

11. Parikh SA, Patel VA, Ratner D. Advances in the management of cutaneous squamous cell carcinoma. F1000Prime Rep. 2014; 6: 70. 